\title{
EFFECTS OF HUMIC AND OXALIC ACID IN WOOD BIODEGRADATION BY Gloeophyllum trabeum
}

\author{
C. POZO ${ }^{1}$ D. CONTRERAS ${ }^{2}$, J. FREER ${ }^{3}$ AND J. RODRÍGUEZ ${ }^{1 *}$

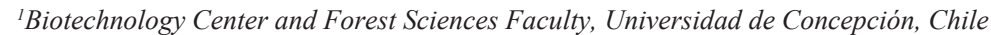 \\ ${ }^{2}$ Department of Analytical and Inorganic Chemistry, Faculty of Chemical Sciences, Universidad de Concepción, Chile \\ ${ }_{3,2}^{3}$ Biotechnology Center and Chemical Sciences Faculty, Universidad de Concepción, Chile \\ (Received: April 14, 2010 - Accepted: October 27, 2010)
}

\begin{abstract}
To degrade wood, brown rot fungi (BRF) have developed a mechanism based on low molar mass iron reducing compounds that promote Fenton reaction. These compounds, also solubilise $\mathrm{Fe}(\mathrm{III})$, in conjunction with oxalic acid, making it available for reaction. It have been postulated that the humic acids participates on wood biodegradation by BRF, acting in a similar way that the fungal compounds. In this work this effect and its interaction with oxalic acid were evaluated. The effect of humic acid and oxalic acid on the biodegradation of radiata pine chips by the BRF Gloeophyllum trabeum was evaluated using a two level factorial design. Absence or concentrations of $5 \mathrm{~g} / \mathrm{L}$ and $0.05 \mathrm{M}$ for humic acid and oxalic acid respectively, were evaluated; temperature $\left(25^{\circ} \mathrm{C}\right)$ and initial $\mathrm{pH}(5.0) \mathrm{were}$ kept constant. The responses were mass loss, holocellulose content and viscosity, measured after 30 days of biodegradation. The effects of the variables were determined using standardized coefficients of the polynomial equation, which were obtained through a multiple linear regression. All experiments were performed in quadruplicate and the obtained model was validated through an ANOVA test with a confidence interval of $95 \%$. Oxalic acid was the factor that has a greater effect on these variables; it was able to extract metals from wood and to inhibit biodegradation when used without further treatment of humic acid. Humic acid impregnation increases the metal content in wood, but did not stimulate the wood biodegradation.
\end{abstract}

Keywords: Brown rot, Wood biodegradation, Humic acid, Oxalic acid, Gloeophyllum trabeum

\section{INTRODUCTION}

Brown rot fungi (BRF) are a group of wood degrading fungi characterized by degrade mainly wood carbohydrate and only modify lignin. In the first biodegradation stages, a fast carbohydrate depolymerization is done, causing a rapid loss of wood strength ${ }^{1}$. Instead to initiate the wood degradation process employing hydrolytic enzymes, BRF have developed a mechanism based on low molar mass iron reducing compounds, which promote Fenton reaction ${ }^{2-7}$.

Fenton reaction $\left(\mathrm{Fe}(\mathrm{II})+\mathrm{H}_{2} \mathrm{O}_{2} \rightarrow \mathrm{Fe}(\mathrm{III})+-\mathrm{OH}+\cdot \mathrm{OH}\right)$ is involved in the wood decay by BRF generating hydroxyl radicals from hydrogen peroxide, that oxidize organic molecules ${ }^{6}$. Low molar mass dihydroxybenzenes (DHBs) and demethylated lignin produced during brown rot degradation of wood, promote Fenton reaction by iron chelation and reduction ${ }^{8}$.

Iron, manganese and copper are involved in the generation of hydroxyl radicals or other oxidizing agents, by Fenton reaction 9 . The total iron concentration in wood is usually lower than $2 \mu \mathrm{mol} / \mathrm{g}$ in non-degraded wood ${ }^{10}$, it can be hardly found as a free cation due to their limited solubility in a neutral $\mathrm{pH}$ environment, but is attached to the wood cellulose ${ }^{11-12}$ forming oxyhydroxides ${ }^{10}$.

Oxalic acid (OA) is an important physiological metabolite, produced by $\mathrm{BRF}$ in high amount ${ }^{13}$. The concentration of OA around the fungal hyphae appears to be tightly regulated and it is essential in the decay process caused by $\mathrm{BRF}^{14}$. Iron can be sequestered from $\mathrm{Fe}$-oxyhydroxides to form $\mathrm{Fe}$-oxalate complexes which can then diffuse into the wood cell wall ${ }^{15}$. Secreted oxalic and other organic acid may also promote brown rot by weathering soil minerals and solubilization of metal cations ${ }^{16-17}$.

Humic substances (HS) constitute the end product of the decomposition of organic residues and represent the major part of organic matter in water, soil and sediment. The HS participate in the majority of reactions that take place in the environment, controlling the transport and transformation of chemical compounds, the formation of complexes by the chelation of metals and other mineral elements, thus influencing the availability of nutrients and the maintenance of soil structure and fertility ${ }^{18}$. HS and their alkaline soluble fraction, the humic acid (HA), should be considered as a supramolecular structure containing several heterogeneous compounds, which have relatively low molecular mass components forming dynamic associations stabilized by hydrophobic interactions and hydrogen bonds ${ }^{19}$.

Due the high amount of functional group containing heteroatoms, especially $\mathrm{O}$ and $\mathrm{N}$, HS has the capacity to interact with metal ions forming complexes of different stability ${ }^{20-21}$. HS are ubiquitous in soils and are often intimately associated with clay minerals from which can uptake minerals to solution phase ${ }^{21}$. It is likely that the humic portion of soil containing the breakdown residues of wood, function as metal-reducing and promoting oxidative reactions in biodegradation processes in $\operatorname{wood}^{8}$.

In the present work, the effect of HA and its interaction with OA on wood biodegradation by Gloeophyllum trabeum was studied by a multivariate method.

\section{MATERIALS AND METHODS}

\section{Materials}

In all experiments and analyses nanopure water (NPW) was used. For culture medium: Soy protein, acid hydrolysate (Sigma); Agar-agar for microbiology (Merck); Malt extract for microbiology (Merck). For chemical analysis (unless otherwise stated, all reagents were p.a. grade): Oxalic acid dihydrate $99 \%$ (Sigma); Nitric acid 65\% (Merck); Sodium chloride $80 \%$ (Fluka); Copper(II) ethylenediamine solution (Merck).

\section{Fungus, inoculum preparation and wood biodegradation}

Wood of radiata pine 20 year old trees were chipped and screened to approximately $2.0 \mathrm{~cm} \times 2.5 \mathrm{~cm} \times 0.5 \mathrm{~cm}$. After biodegradation, the wood chips were collected, and stored in dry conditions for further characterization.

Gloeophyllum trabeum (ATCC 11539) cultures were maintained in water at $4^{\circ} \mathrm{C}$ and before experiments it was growth in agar plates by 7 days at $25^{\circ} \mathrm{C}$. Erlenmeyer flasks $(2000 \mathrm{~mL})$ containing $200 \mathrm{~mL}$ medium composed of $2 \%$ malt extract and $0.5 \%$ soybean peptone were inoculated with 20 discs $(8 \mathrm{~mm}$ diameter) of a $G$. trabeum culture on agar medium. These liquid cultures were maintained static for 15 days at $25^{\circ} \mathrm{C}$. The mycelial pellets were then removed by filtration and washed with $500 \mathrm{~mL}$ sterile water. The washed mycelium from several flasks was blenderized with $100 \mathrm{~mL}$ sterilized water for $15 \mathrm{~s}$ (three cycles), and used to inoculate the wood chips.

Humic acid (HA) was obtained from soil collected in a forest close to Concepción, Chile (36 50'29' $\mathrm{S}, 73^{\circ} 1{ }^{\prime} 33^{\prime}$ 'O) according to the modified method of Gryndler et al ${ }^{22}$ to avoid possible toxic effects of extractant traces on fungi. All analysis was done using a Beckman CS-6R centrifuge and 500 $\mathrm{mL}$ bottles. A portion of $100 \mathrm{~g}$ of soil was shaken in $1 \mathrm{~L}$ of $0.1 \mathrm{M} \mathrm{NaOH}$. After a $24 \mathrm{~h}$ extraction at $25^{\circ} \mathrm{C}$, the alkaline solution was centrifuged at $2050 \mathrm{~g}$ for 30 min and filtered through $0.22 \mu \mathrm{m}$ cellulose acetate filters to remove minerals components. The clean, dark-coloured filtrate was acidified by concentrated hydrochloric acid to $\mathrm{pH} 2.0$. Suspension was centrifuged at $2050 \mathrm{~g}$ for 30 
min. The insoluble fraction was separated and frozen at $-4^{\circ} \mathrm{C}$ overnight and subsequently unfrozen. Precipitate was separated by filtration through $0.22 \mu \mathrm{m}$ cellulose acetate filters and air-dried.

For the fungal treatments, $50 \mathrm{~g}$ (on dry basis) of chips were placed in each stationary tray bioreactor according to method proposed by Akhtar et al ${ }^{23}$. The bioreactor consisted of a plastic tray with dimensions of $14.5 \mathrm{~cm}$ (length) $\times 10$ $\mathrm{cm}$ (width) x $5 \mathrm{~cm}$ (height). For the control, $50 \mathrm{~g}$ (on dry basis) of chips were put in a similar bioreactor. Each stationary tray bioreactor was placed inside a polypropylene containment bag, autoclaved for $15 \mathrm{~min}$ at $121^{\circ} \mathrm{C}$, and cooled to room temperature.

Inoculation of wood chips was performed after impregnation and sterilization at $121^{\circ} \mathrm{C}$ for $15 \mathrm{~min}$ and cooled to room temperature. Mycelium mass/wood ratio of $1 \mathrm{~g} / \mathrm{kg}$ (on dry basis) was added to the wood chips in the appropriate bioreactors and mixed thoroughly.

Cultures were incubated at $25^{\circ} \mathrm{C}$ statically during biodegradation for period of 30 days. The control's bioreactors were treated identically to the inoculated bioreactors, except it was not inoculated. Weight loss was calculated based on the initial and final dry weights.

\section{Wood impregnation}

All samples were soaked in $\mathrm{NaOH} 0.1 \mathrm{M}$ (one liter of solution per $100 \mathrm{~g}$ of dry wood) 16 samples by $12 \mathrm{~h}$ and the rest by $24 \mathrm{~h}$. These two groups of samples were subsequently treated in a similar way. The group was separated into two sets of samples, one was neutralized with a similar volume of $\mathrm{HNO}_{3} 0.1 \mathrm{M}$ and the other with con OA $0.05 \mathrm{M}$. Half of each previous group was removed, drained and impregnated again with a solution of $5 \mathrm{~g}$ (on dry basis) of HA per liter of $\mathrm{NaOH} 0.1 \%$ with a final $\mathrm{pH}=5$ adjusted with concentrated $\mathrm{HNO}_{3}$. The final $\mathrm{pH}$ of all samples was similar to 5. Finally all samples were drained, inoculated and sterilized as explained previously. After biodegradation period the samples were dried at $50^{\circ} \mathrm{C}$ for $48 \mathrm{~h}$ and one week at $25^{\circ} \mathrm{C}$ until reaching $\sim 10 \%$ (w/w) moisture (Fig 1 ).

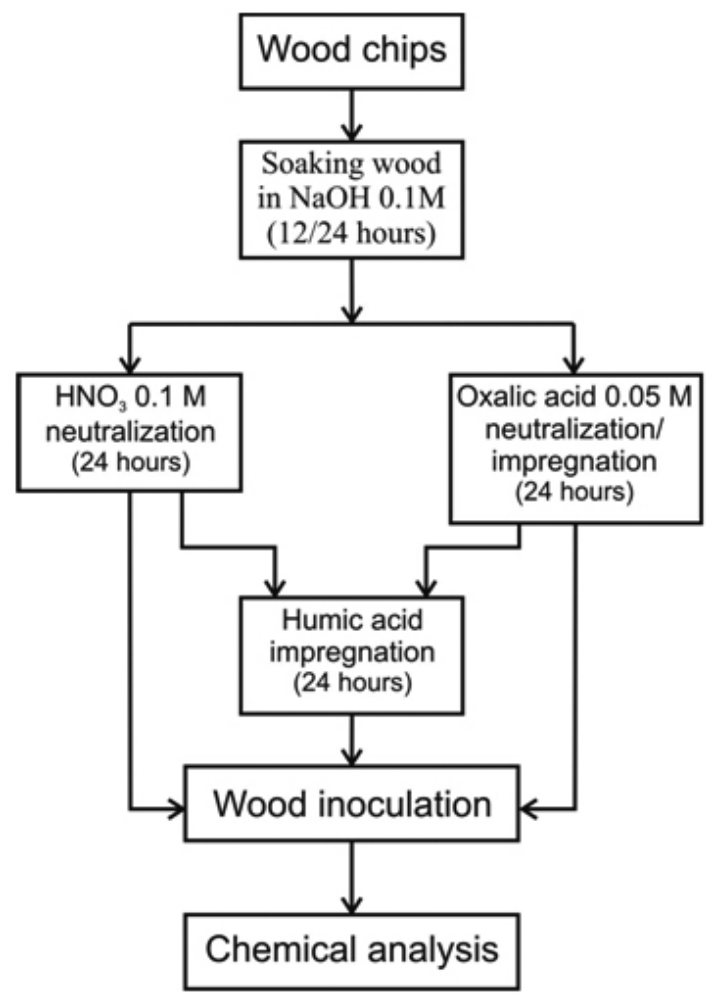

Figure 1. The general outline of the experiment.

Chemical analysis of the wood chips and humic acid

For chemical analysis, air-dried samples were milled in a knife mill (Manesco \& Ranieri) through a 18 mesh. To obtain a representative sample, each sample was mixed and partitioned using a quartering method ${ }^{24}$. Approximately $1 \mathrm{~g}$ of sample was extracted with $99 \%$ acetone for $16 \mathrm{~h}$ in a Soxhlet apparatus following standard method (TAPPI Test Method T 280 pm-99).

Chlorite holocellulose was prepared using the procedure following standard method (TAPPI Standard T-9m-54). Volumes and weights called for in the procedure were scaled in proportion to the mass of air-dried wood used in each preparation. The viscosity of different samples of holocellulose was measured by standard method (TAPPI Test Method T $230 \mathrm{om}-04$ ) using cupriethylendiamine (CED) as a solvent and an Ostwald viscometer, to give an indication of the average degree of polymerization of the holocellulose. Intrinsic viscosities were obtained using the Solomon-Ciuta equation ${ }^{25}$.

The determination of metals was made from ash samples digested with hot nitric acid pa $50 \% \mathrm{v} / \mathrm{v}$. The cold solution was filtered through qualitative paper $\mathrm{N}^{\circ} 2$ and transferred to $50 \mathrm{~mL}$ volumetric flask. The quantification of metals $\mathrm{Fe}$, $\mathrm{Cu}$ and $\mathrm{Mn}$ using atomic spectrometry was used according to Chilean standard method (ICP 2313/25).

For $\mathrm{pH}$ determinations, $2 \mathrm{~g}$ of wood chips were soaked with $12.5 \mathrm{~mL}$ of permanganate bi-distilled water ( $\mathrm{pH}$ of water previously adjusted to 7.0 ) for 48 h. After this period, the resulting aqueous extract was recovered by filtration through fine filter paper and its $\mathrm{pH}$ was measured ${ }^{26}$.

An ANOVA test was performed to determine whether the experiments differed significantly. A multiple comparison procedure (multiple range test) was then used to find which means were significantly different at the 95.0\% confidence level. The method used to discriminate among the means was Fisher's least significant difference (LSD) procedure. All statistics were obtained using Statgraphics Plus 3.1 software (Manugistics Inc., Rockville, USA).

\section{Multivariate analysis}

In order to identify the significant parameters in the multivariate analysis, the influence of three factors on chemical properties of brown rotted wood were investigated in a full factorial design ( 2 levels) as given by Otto ${ }^{27}$.

The factors investigated were $\mathrm{OA}$ impregnation $\left(\mathrm{X}_{1}\right)$ and $\mathrm{HA}$ impregnation $\left(\mathrm{X}_{2}\right)$ and $\mathrm{NaOH}$ swelling $\left(\mathrm{X}_{3}\right)$. The response was mass loss $\left(\mathrm{Y}_{1}\right)$, holocellulose $\left(\mathrm{Y}_{2}\right)$, viscosity $\left(\mathrm{Y}_{3}\right)$ expressed as a percentage of the initial amount. The $\mathrm{pH}$ of wood after treatment was measured for each experiment. The experimental order was randomized. Each experiment was carried out in quadruplicated requiring a total of 32 experimental runs.

For discrete variables $\mathrm{X}_{1}$ and $\mathrm{X}_{2}$ extreme values are without impregnation $(-1)$ and with impregnation $(+1)$. For $\mathrm{X}_{3}$ the extreme values are $12(-1)$ and $24 \mathrm{~h}$ $(+1)$, a first -order function that describes the system behavior was determined by a Multiple Lineal Regression method (MLR). The statistical validation was performed by an ANOVA test with a $95 \%$ confidence. The design and the analysis of experiments were performed using the software Modde 7.0.

\section{RESULTS AND DISCUSSIONS}

\section{$\mathrm{NaOH}$ swelling}

One way to facilitate the incorporation of organic compounds into the wood is submitted to alkaline action where acetyl groups, which are present in the galactoglucomannans of softwoods, are quickly removed. It increases the wood swelling and therefore the accessibility to the cell wall ${ }^{28-29}$. Even the previous mention, not effect in wood decay was observed after $\mathrm{NaOH}$ swelling at 12 or $24 \mathrm{~h}$. In this way this variable was excluded from further analysis of the multivariate analysis.

\section{Multivariate analysis}

The experimental design and chemical composition of brown rotted wood is shown in Table 1. The mass loss varies between 1.5 and $12.6 \%$ for 30 days of biodegradation. Holocellulose content and viscosity were inversely related to the mass loss. The lower $\mathrm{pH}$ in more biodegraded samples can be associates with organic acid production by BRF during its metabolism ${ }^{10}$. The decreased viscosity is related to holocellulose depolymerization produced by brown rot fungi mainly in early stages of biodegradation ${ }^{30}$.

The coefficient of each variable and their interaction in the polynomial responses, are shown in Table 2 . The coefficients for $X_{1}$ and $X_{2}$ their interaction were significant $(P<0.05)$. 
The goodness of fit $\left(\mathrm{R}^{2}\right)$ and prediction $\left(\mathrm{Q}^{2}\right)$ are used as indicative criteria of the polynomial fit. The first is an overestimated and the last an underestimated measure of the polynomial performance ${ }^{27}$. There was a large variation in the performance parameters; $\mathrm{R}^{2}$ varied between 0.72 for viscosity and 0.92 for mass loss, while $\mathrm{Q}^{2}$ ranging from 0.63 for viscosity to 0.90 for mass loss.

The coefficient of OA impregnation term $\left(\mathrm{X}_{1}\right)$ shows the highest value for the polynomials, which had a negative effect on mass loss. The $\mathrm{Fe}, \mathrm{Mn}$ and $\mathrm{Cu}$, solubilized in the complexes were leaching out of wood when the excess water is removed (table 1). Also high oxalate concentrations decrease the transition metals availability by formation of stable complexes ${ }^{9}$ resulted in inhibition of iron reduction and Fenton reaction ${ }^{9,31}$.
The coefficients of HA impregnation term $\left(\mathrm{X}_{2}\right)$ were positive for wood biodegradation. This is according to the increased concentration of $\mathrm{Fe}$ in experiment, when only HA was added to wood sample. Also on experiment 4 there was a lower Fe concentration because the wood was previously treated with OA. There is not a significant increasing in the biodegradation when HA is used, however the decreasing of biodegradation by OA was significantly lower when HA was added (experiments 2 and 4, table 1). This positive interaction is confirmed by the values of interaction coefficient $\left(\mathrm{X}_{1} \mathrm{X}_{2}\right)$ in the polynomials. Otherwise, the HA can reduce $\mathrm{Fe}$ (III) and produce $\mathrm{H}_{2} \mathrm{O}_{2}{ }^{32}$, these compound could increase the fungal Fenton based oxidative system for wood biodegradation. In this way, HA could neutralize the OA negative effect over wood biodegradation by both $\mathrm{Fe}$ mobilization and Fenton reaction promoting.

Table 1. Full factorial screening design and experimental results.

\begin{tabular}{|c|c|c|c|c|c|c|c|c|c|}
\hline \multirow[t]{2}{*}{ Experiment } & \multicolumn{2}{|c|}{ Factors } & \multicolumn{7}{|c|}{ Responses $^{1}$} \\
\hline & $\begin{array}{c}\text { Oxalic } \\
\text { Acid }\left(\mathbf{X}_{1}\right)\end{array}$ & $\begin{array}{c}\text { Humic } \\
\text { Acid }\left(\mathrm{X}_{2}\right)\end{array}$ & $\begin{array}{c}\text { Mass Loss } \\
(\%)\end{array}$ & $\begin{array}{c}\text { Holocellulose } \\
\text { (\%) }\end{array}$ & $\begin{array}{l}\text { Viscosity } \\
\text { (dL/g) }\end{array}$ & $\mathbf{p H}$ & $\mathrm{Fe}(\mu \mathrm{M} / \mathrm{g})$ & Mn $(\boldsymbol{\mu M} / \mathbf{g})$ & $\mathrm{Cu}(\mu \mathrm{M} / \mathrm{g})$ \\
\hline 1 & -1 & -1 & $12.6 \pm 1.3$ & $57.3 \pm 1.3$ & $2.4 \pm 0.4$ & $4.4 \pm 0.1$ & $0.31 \pm 0.03^{\mathrm{a}}$ & $0.57 \pm 0.05^{\mathrm{a}}$ & $0.049 \pm 0.014^{\mathrm{a}, \mathrm{b}}$ \\
\hline 2 & +1 & -1 & $1.5 \pm 0.3$ & $66.7 \pm 0.7$ & $4.4 \pm 0.4$ & $5.4 \pm 0.1$ & $0.18 \pm 0.02^{\mathrm{b}}$ & $0.22 \pm 0.02^{b}$ & $0.015 \pm 0.002^{\mathrm{c}}$ \\
\hline 3 & -1 & +1 & $12.1 \pm 0.5$ & $57.6 \pm 0.7$ & $2.4 \pm 0.1$ & $4.2 \pm 0.1$ & $2.15 \pm 0.14^{\mathrm{c}}$ & $0.59 \pm 0.04^{\mathrm{a}}$ & $0.056 \pm 0.004^{b}$ \\
\hline 4 & +1 & +1 & $9.8 \pm 1.4$ & $58.9 \pm 1.5$ & $3.0 \pm 0.5$ & $4.3 \pm 0.1$ & $1.31 \pm 0.09^{\mathrm{d}}$ & $0.26 \pm 0.01^{\mathrm{b}}$ & $0.032 \pm 0.011^{\mathrm{d}}$ \\
\hline Control $^{2}$ & & & & & & & $0.31 \pm 0.03^{\mathrm{a}}$ & $0.57 \pm 0.05^{\mathrm{a}}$ & $0.049 \pm 0.014^{\mathrm{a}, \mathrm{b}}$ \\
\hline Humic Acid ${ }^{3}$ & & & & & & & $192.32 \pm 18.52$ & $4.12 \pm 0.22$ & $0.93 \pm 0.05$ \\
\hline
\end{tabular}

${ }^{1}$ Data are shown as mean (4 repetitions) \pm confidence interval

${ }^{2}$ Metal contents in undecayed wood chips of radiata pine

${ }^{3}$ Metal contents in humic acid obtained from soil

${ }^{\text {a-d }}$ Means within a row whit different superscripts differ significantly $(P<0.05)$

Table 2. Coefficient values and polynomial fit parameters

\begin{tabular}{|c|c|c|c|}
\hline \multirow[b]{2}{*}{ Coefficient } & \multicolumn{3}{|c|}{ Responses $^{\mathrm{a}}$} \\
\hline & $\begin{array}{l}\text { Mass Loss } \\
(\%)\end{array}$ & $\begin{array}{c}\text { Holocellulose } \\
(\%)\end{array}$ & Viscosity $(d L / g)$ \\
\hline Constant & $9.00 \pm 0.51$ & $60.14 \pm 0.56$ & $3.05 \pm 0.20$ \\
\hline Oxalic acid $\left(X_{1}\right)$ & $-3.37 \pm 0.51$ & $2.66 \pm 0.56$ & $0.66 \pm 0.20$ \\
\hline Humic acid $\left(\mathrm{X}_{2}\right)$ & $1.96 \pm 0.51$ & $-1.86 \pm 0.56$ & $-0.35 \pm 0.20$ \\
\hline$X_{1} * X_{2}$ & $2.27 \pm 0.51$ & $-2.02 \pm 0.56$ & $-0.34 \pm 0.20$ \\
\hline \multicolumn{4}{|l|}{$\begin{array}{c}\text { Polynomial fit } \\
\text { parameters }\end{array}$} \\
\hline$R^{2}$ & 0.92 & 0.87 & 0.72 \\
\hline$Q^{2}$ & 0.90 & 0.83 & 0.63 \\
\hline
\end{tabular}

\section{CONCLUSIONS}

From the polynomial analysis can be concluded that OA have a negative effect over biodegradation extend, but HA partially neutralize this effect through a synergic interaction. The negative effect of OA was related with metals depletion from wood and synergic interaction with HA was associated with metals increasing in the wood, especially Fe. HA alone did not present a stimulation on the wood biodegradation.

\section{ACKNOWLEDGMENT}

Financial support for this work was provided by FONDECYT (Grant No. 1080303) and Conicyt (Claudio Pozo PhD fellowship) is gratefully acknowledged.

\section{REFERENCES}

1. B. Goodell, in Wood deterioration and preservation. ACS Symposium series 845, B. Goodell, D. D. NicholasT. P. Schultz eds., Washington DC, 2003; pp. 97-118.

2. S. M. Hyde, P. M. Wood, Microbiology 143, 259, (1997).

3. B. Goodell, J. Jellison, J. Liu, G. Daniel, A. Paszczynski, F. Fekete, S. Krishnamurthy, L. Jun, G. Xu, J. Biotechnol. 53, 133, (1997).

4. Z. Kerem, K. A. Jensen, K. E. Hammel, FEBS Lett. 446, 49, (1999).

5. K. A. Jensen, Jr., C. J. Houtman, Z. C. Ryan, K. E. Hammel, Appl. Environ. Microbiol. 67, 2705, (2001).

6. K. E. Hammel, A. N. Kapich, J. K. A. Jensen, Z. C. Ryan, Enzyme Microb. Technol. 30, 445, (2002).

7. J. Rodriguez, A. Ferraz, M. P. Mello, in Wood Deterioration and Preservation. ACS Symposium Series 845, B. Goodell, D. D. NicholasT. P. Schultz eds., Washington DC 2003; pp. 154-174.

8. B. Goodell, G. Daniel, J. Jellison, Y. Qian, Holzforschung 60, 630, (2006).

9. W. P. Henry, in Wood deterioration and preservation. ACS Symposium series 845 , B. Goodell, D. D. NicholasT. P. Schultz eds., Washington DC, 2003; pp. 175-195.

10. J. Jellison, J. Connolly, B. Goodell, B. Doyle, B. Illman, F. Fekete, A. Ostrofsky, Int. Biodeterior. Biodegrad. 39, 165, (1997).

11. G. Xu, B. Goodell, J. Biotechnol. 87, 43, (2001).

12. S. M. Kremer, P. M. Wood, Eur. J. Biochem. 208, 807, (1992).

13. F. Green, M. J. Larsen, J. E. Winandy, T. L. Highley, Material und Organismen 26, 191, (1991).

14. J. A. Micales, Int. Biodeterior. Biodegrad. 39, 125, (1997).

15. V. Arantes, Y. Qian, A. M. F. Milagres, J. Jellison, B. Goodell, Int. Biodeterior. Biodegrad. 63, 478, (2009).

16. G. M. Gadd, Mycol. Res. 111, 3, (2007).

17. E. P. Burford, M. Fomina, G. M. Gadd, Mineral. Mag. 67, 1127, (2003).

18. A. Piccolo, in Humic Substances in Terrestrial Ecosystems, A. Piccolo eds., Elsevier, Amsterdam, 1996; pp. 225-264.

19. R. Sutton, G. Sposito, Environ. Sci. Technol. 39, 9009, (2005). 
20. G. Davies, A. Fataftah, A. Cherkasskiy, E. A. Ghabbour, A. Radwan, S. A. Jansen, S. Kolla, M. D. Paciolla, L. T. Sein, W. Buermann, M. Balasubramanian, J. Budnick, B. Xing, J. Chem. Soc., Dalton Trans. 21, 4047, (1997).

21. J. F. Stevenson, Humus Chemistry: Genesis, Composition, Reactions, John Wiley \& Sons, New York, 1994.

22. M. Gryndler, H. Hršelová, R. Sudová, H. Gryndlerová, V. Řezáčová, V. Merhautová, Mycorrhiza 15, 483, (2005).

23. M. Akhtar, C. Attridge, C. G. Myers, K. T. Kirk, R. A. Blanchette, Tappi J. 75, 105, (1992).

24. H. David, Modern analytical chemistry, New York, USA, 2000

25. O. F. Solomon, I. Z. Ciuta, J. Appl. Polym. Sci. 6, 683 (1962).
26. B. L. Browning, Methods of Wood Chemistry (Vol. I) Interscience Publishers, New York, 1967.

27. M. Otto, Chemometrics: Statistics and Computer Application in Analytical Chemistry, Wiley-VCH, Weinheim, Germany, 2007.

28. E. Sjöström, J. Janson, P. Haglund, B. Enström, J. Polym. Sci., Part C: Polym. Sym. 11, 221, (1965)

29. M. Zanuttini, V. Marzocchi, P. Mocchiutti, M. Inalbon, Holz Roh Werks. 63, 149, (2005).

30. M. R. Suzuki, C. G. Hunt, C. J. Houtman, Z. D. Dalebroux, K. E. Hammel, Environ. Microbiol. 8, 2214, (2006).

31. E. Varela, M. Tien, Appl. Environ. Microbiol. 69, 6025, (2003).

32. B. Palenik, O. C. Zafiriou, F. M. M. Morel, Limnol. Oceanogr. 32, 1365, (1987) 